\title{
EDITORIAL
}

\section{Maternal Near Miss: An Indicator for Maternal Health and Maternal Care}

The standard indicator used for the measurement of maternal health is the Maternal Mortality Ratio, defined as the ratio of the number of maternal deaths per 100,000 live births. The global maternal mortality ratio is $210 /$ 100,000 live births while it is about 240 in developing countries as compared to $14 / 100,000$ in developed countries $^{1}$. Officially declared MMR in Bangladesh is 176/100,000 live births ${ }^{2}$. Main causes of maternal deaths are Haemorrhage, Pregnancy Induced Hypertension, Sepsis, Obstructed labour, abortion, other direct \& indirect causes and unclassified ${ }^{3,4}$.

The current main approaches to the reduction of maternal deaths are emergency obstetric care, skilled care by skilled birth attendants and unmet obstetric need. As the mortality rates are consistently decreasing, the focus is shifted on maternal near miss which describes severe maternal morbidity. Maternal mortality is the tip of the iceberg; there is a large base of the severe acute maternal morbidity (SAMM), which remains undescribed ${ }^{5}$.

A maternal near miss (MNM) is an event in which a pregnant woman who nearly died but survived by chance that occurred during pregnancy, childbirth or within 42 days of termination of pregnancy. In practical terms, Women are considered near miss cases when they survive from life-threatening conditions (i.e. organ dysfunction) because of the hospital care she received.

Recent review on articles between January 2004 and December 2010 the prevalence rates of maternal near miss varied between $0.6 \%$ and $14.98 \%$ for diseasespecific criteria, between $0.04 \%$ and $4.54 \%$ for management-based criteria and between $0.14 \%$ and $0.92 \%$ for organ-based dysfunction based on Mantel criteria. The rates are higher in low-income and middleincome countries of Asia and Africa ${ }^{6,7}$.

Near miss is more common than maternal deaths ${ }^{5}$. For every woman who dies, many more will survive but often suffer from lifelong disabilities. Over the last decade, the identification of cases of severe maternal morbidity has emerged as a promising complement or alternative to the investigation of maternal deaths ${ }^{8}$. It has been suggested that with the observed decline in maternal mortality, analysis of well defined near-miss cases may be a more sensitive measure of the standard hospital based obstetric care and for assessing the incidence of life threatening complications.

Severe life threatening obstetric complications are ruptured uterus, pulmonary embolism, sepsis, eclampsia, obstetric haemorrhage, anemia related conditions, abortion, heart failure, ruptured ectopic, amniotic fluid embolism and anesthesia ${ }^{9,10}$.

The causes of near miss vary in different geographical areas of the world and also there are variations within countries. Hemorrhage, hypertensive disorders, sepsis and obstructed labor are the most important causes in the developing countries. Causes of near miss are similar to causes of maternal deaths prevailing in the area. Hemorrhage was the leading cause of maternal deaths in Africa (33.9\%) and in Asia (30.8\%) while in Latin America and the Caribbean, hypertensive disorders were responsible for $25 \%$ deaths. Anemia was reported as an important cause in $12.8 \%$ deaths in Asia, 3.7\% in Africa and none in the developed countries ${ }^{8,11}$.

To understand the gaps in access to adequate management of obstetric emergencies leading to severe maternal complications and death three delays have been identified.

First delay is in deciding to seek care by the woman or her family, as they are unaware of the need for care. This occurs as the danger signs are not recognized or there is lack of support of the family.

The second delay is in reaching the adequate health care facility as the services may not exist or may be inaccessible for reasons such as distance, lack of transport, cost or socio economic barriers.

The third delay occurs in receiving adequate care at that facility resulting from errors in: diagnosis and clinical 
decision making, lack of medical supplies and of staff proficiency in the management of obstetric emergencies $^{12,13,14}$.

In developing countries, about $75 \%$ of the woman with severe obstetric morbidity is in a critical condition upon arrival, underscoring the significance of first two delays. Availability, accessibility, cost of health care and behavioral factors play an important role in the utilization of maternal health services.

Recently, a WHO Expert Group has suggested a uniform set of identification criteria for maternal near miss cases aiming to facilitate the reviews of these cases ${ }^{15,16,17}$.

Disease-based: by clinical criteria related to a specific disease entity such as severe eclampsia or haemorrhage.

Management-based: a specific intervention such as admission to an intensive care unit or procedure such as a hysterectomy or massive blood transfusion.

Organ-dysfunction-based: a method whereby organ system dysfunction (circulatory, respiratory, cardiac, renal, hepatic, central nervous, metabolic and hematological) such as shock or respiratory distress is identified. The organ-system dysfunction based approach is considered the most promising frame for establishing a standard set of criteria.

The WHO near miss approach is a standardized method which is implemented In three steps in a cyclical manner: (1) base line assessment (or reassessment) (2) situation analysis and (3)interventions for improving health care.

A stepwise implementation of the maternal near miss concept can be done.

Step 1: Raising awareness and persuasion to conduct routine maternal near miss reporting (opinion leaders, educational meetings, printed materials, use of the surveillance tool).

Step 2: Confidential inquiries or Severe Maternal Outcome case review (audit and feedback).

Step 3: Addressing identified problems, prospective surveillance of life-threatening conditions and promotion of evidence-based practices (quality of care improvement).

In any setting, women who develop severe acute complications during pregnancy share many pathological and circumstantial factors. While some of these women die, a proportion of them narrowly escape death. Thus, there is a need for application of the maternal near-miss concept for assessment of maternal health and quality of maternal care. Beyond the conduct of the near-miss approach, multifaceted tailored approaches may be needed.

to improve the quality of care within the health system. In selected areas and facilities, these approaches can include the implementation of evidence-based guidelines and the use of reminders, opinion leaders' endorsement, and continued audit and feedback to achieve behavioral and process changes.

(J Bangladesh Coll Phys Surg 2018; 36: 1-3)

\author{
Professor Kohinoor Begum \\ Councillor, BCPS and \\ Professor \& Head, Dept. of Obst. and Gynae \\ Popular Medical College \\ House No-25, Road No-02 \\ Dhanmondi R/A, Dhaka \\ Bangladesh
}

\section{References:}

1. World Health Organization. Geneva, Switzerland: World Health Organization; 2010. pp. 15-6.

2. WHO, UNICEF, UNFPA, World Bank Group, and United Nations Population Division .Maternal Mortality Estimation Inter-Agency Group: Maternal Mortality in 1990-2015.WHO 2015

3. Khan KS, Wojdyla D, Say L, Gülmezoglu AM, Van Look PF. WHO analysis of causes of maternal death: A systematic review. Lancet. 2006;367:1066-74. [PubMed]

4. Walraven G, Telfer M, Rowley J, Ronsmans C. Maternal mortality in rural Gambia: Levels, causes and contributing factors. Bull World Health Organ. 2000;78:603-13. [PMC free article] [PubMed]

5. Souza JP, Cecatti JG, Parpinelli MA, Serruya SJ, Amaral E. Appropriate criteria for identification of near-miss maternal morbidity in tertiary care facilities: A cross sectional study. BMC Pregnancy Childbirth. 2007;7:20. [PMC free article] [PubMed]

6. Say L, Pattinson RC, Gülmezoglu AM. WHO systematic review of maternal morbidity and mortality: The prevalence of severe acute maternal morbidity (near miss) Reprod Health. 2004;1:3. [PMC free article] [PubMed]

7. Tunçalp O, Hindin MJ, Souza JP, Chou D, Say L. The prevalence of maternal near miss: A systematic review. BJOG. 2012;119:653-61. [PubMed]

8. Khan KS, Wojdyla D, Say L, Gülmezoglu AM, Van Look PF. WHO analysis of causes of maternal death: A systematic review. Lancet. 2006;367:1066-74. [PubMed] 
9. Chhabra P. Maternal near miss: an indicator for maternal health and maternal care. Indian J Community Med. 2014 Jul;39(3):132-7.

10. Almerie Y, Almerie M Q, Matar H E, Shahrour Y, Chama, AA A, Abdulsalam A. Obstetric near-miss and maternal mortality in maternity university hospital, Damascus, Syria: a retrospective study. Available from https://bmcpregnancy childbirth. biomedcentral.com/articles/10.1186/1471-2393-10-65

11. Walraven G, Telfer M, Rowley J, Ronsmans C. Maternal mortality in rural Gambia: Levels, causes and contributing factors. Bull World Health Organ. 2000;78:603-13. [PMC free article] [PubMed]

12. Ronsmans C, Fillipi V. Beyond the Numbers: Reviewing Maternal Deaths and Complications to Make Pregnancy Safer. Geneva, Switzerland: World Health Organization; 2004. Reviewing severe maternal morbidity: Learning from survivors from life threatening complications; pp. 103-24.

13. Pattinson RC, Buchmann E, Mantel G, Schoon M, Rees H. Can enquiries into severe acute maternal morbidity act as a surrogate for maternal death enquiries? BJOG. 2003;110:889_ 93. [PubMed]

14. Filippi V, Brugha R, Browne E, Gohou V, Bacci A, De Brouwere $\mathrm{V}$, et al. Obstetric audit in resource-poor settings: Lessons from a multi-country project auditing 'near miss' obstetrical emergencies. Health Policy Plan. 2004;19:57-66. [PubMed]

15. Say L, Pattinson RC, Gülmezoglu AM. WHO systematic review of maternal morbidity and mortality: The prevalence of severe acute maternal morbidity (near miss) Reprod Health. 2004;1:3. [PMC free article] [PubMed]

16. Tunçalp O, Hindin MJ, Souza JP, Chou D, Say L. The prevalence of maternal near miss: A systematic review. BJOG. 2012;119:653-61. [PubMed]

17. Say L, Souza JP, Pattinson RC. WHO working group on Maternal Mortality and Morbidity classifications. Maternal near miss - Towards a standard tool for monitoring quality of maternal health care. Best Pract Res Clin Obstet Gynaecol. 2009;23:287-96. [PubMed] 